\title{
O SIGNIFICADO DE APRENDER PARA ALUNOS DE UMA ESCOLA AGROTÉCNICA ${ }^{1}$
}

\author{
The meaning of learning for students of an \\ agrotechnical high school
}

\author{
Rita de Cássia Pereira Borges ${ }^{2}$ \\ Washington Luiz Pacheco de Carvalho ${ }^{3}$
}

\begin{abstract}
Resumo: Este trabalho de pesquisa se propôs a desvelar o significado de "aprender" entre os alunos de uma escola agrotécnica. Como aquilo que se busca compreender são os significados de aprender, fezse necessário ir ao encontro de sujeitos que vivenciam este fenômeno e deles obter-se descrições sobre suas vivências. Como procedimento metodológico, foi utilizada a pesquisa qualitativa na modalidade fenomenológica. Os instrumentos que possibilitaram a constituição de dados foram a observação de alunos em situaçôes vivenciadas na sala de aula e entrevistas. Com o objetivo de se desvelar o fenômeno investigado, buscou-se sua estrutura nos discursos, nas descrições ingênuas coletadas, nos acompanhamentos e nas entrevistas, possibilitando-se, assim, o acesso ao vivido. Captada pela escrita e pela fala, as descriçóes fornecem indicativos de como o sujeito percebe o fenômeno, o que vai se revelando à medida que as descriçōes são analisadas. Assim, procedeu-se às análises idiográfica e a nomotética. Os significados a que se chegou foram perseguidos num processo de redução fenomenológica. Na busca das convergências e divergências de significados entre os alunos, procurou-se evidenciar os invariantes e as categorias que expressam aspectos relevantes do fenômeno estudado. As convergências a que se chegou evidenciaram significados de aprender que abrangem "o sentido de aprender", as "condiçôes para aprender" e "relações afetivo-relacionais no aprender". Por fim, elaborou-se uma interpretação e uma reflexão a respeito do significado de aprender para os alunos e a relação desse significado com situações vividas em uma escola agrotécnica.
\end{abstract}

Palavras-chave: fenomenologia. significado de aprender. escola agrotécnica.

Abstract: This study aimed at revealing the meaning of learning among students of a technical High School. As what was intended to be understood were the meanings of learning, it was necessary to obtain descriptions of the people who were experiencing this phenomenon.. A phenomenological approach was used and the data was comprised of observations and interviews. From these, the structures of the phenomena were described inside the discourses, in the naive descriptions, in the class observations and in the interviews. From the ideographic and nomothetic analysis of the descriptions, it was possible to obtain hints of how the students understood the phenomena. So, the meanings were obtained in a phenomenological reduction process. In the search of convergences and divergences of meanings among the students, the invariance and the categories that expressed relevant aspects of the phenomena were emphasized. The convergences obtained showed that the meaning of learning encompasses "the sense of learning", the "context of learning" and the "affectiverelational relationship in learning". As a conclusion, a reflection about the meaning of learning for those students and its possible implication to knowledge is suggested.

Keywords: phenomenology. meaning of learning. agrotechnical school.

\footnotetext{
${ }^{1}$ Apoio: Escola Agrotécnica Federal de Cáceres - Mato Grosso, (Capes/ PICDTec).

${ }^{2}$ Mestre no Programa de Pós-Graduação em Educação para a Ciência, Faculdade de Ciências, Universidade EstadualPaulista, Campus de Bauru, São Paulo, e Professora de Física da Escola Agrotécnica Federal de Cáceres-Mato Grosso. E-mail: maribor@usp.br

${ }^{3}$ Professor Adjunto do Departamento de Física e Química da Faculdade de Engenharia, Campus de Ilha Solteira, e do Programa de Pós-Graduação em Educação para a Ciência, Faculdade de Ciências, Campus de Bauru, Universidade Estadual Paulista, São Paulo. E-mail:washcar@dfq.feis.unesp.br
} 
Borges, R. C. P.; Carvalho, W. L. P.

\section{Introdução: como nasceu a interrogação}

A reflexão que aqui apresentamos teve origem na vivência de uma professora de Física e na preocupação em compreender o vivido no processo de ensino e aprendizagem na Escola Agrotécnica Federal de Cáceres - EAFC, no Estado do Mato Grosso.

Algumas situações que se apresentaram nessa vivência nos levavam a inquietações como: o fato do professor "ensinar" algo a um aluno, enquanto ele não percebe significado no que lhe é "ensinado"; o fato de o sujeito que aprende não se perceber como sujeito desse aprender, ou como agente de transformaçóes sociais; o fato de os estudantes mostrarem-se tão resistentes ao esforço pessoal no sentido de aprender e receptivos à memorização; o fato de mostrarem-se, no convívio em sala de aula, altamente resistentes a discussōes, apresentarem seus pontos de vista, exporem suas idéias, argumentarem. Na tentativa de fazer algo para compreender essas situaçôes vividas, primeiramente passamos a investigar o ensinar. A reflexão sobre este ensinar acabou nos conduzindo a projetos, concepçôes e propostas de ensino, juntamente com suas avaliaçôes.

Essa reflexão não nos levou a compreender as situaçóes vividas, mas nos conduziu a procurar entender o que viria a ser "aprender" para os alunos de uma escola técnica; nos levou a buscar pelo significado de aprender para os estudantes, a refletir a respeito das relações entre esse sentido de aprender e a aprendizagem desses alunos, a buscar nas concepçôes desveladas um sentido às situaçôes vividas. Nesse intenso processo de buscas, nasceu e se definiu a opção por uma abordagem fenomenológica da pesquisa.

\section{A metodologia}

Para saber o que faz sentido para o sujeito, fez-se necessário ir-à-coisa-mesma, ou seja, sendo o fenômeno investigado o significado de aprender para os alunos de uma escola agrotécnica, foi necessário ir aos alunos, aos sujeitos atribuidores de significados, aqueles que vivem a situação do aprender, aqueles que percebem, sujeitos que são capazes de expor aquilo que thes faz sentido, que descrevem, que relatam o percebido no seu mundo-vida ${ }^{4}$.

$\mathrm{Na}$ busca pelos significados relevantes para o aluno sobre o seu processo de aprender, acompanhamos os estudantes da segunda série do curso "técnico agrícola" da EAFC, habilitação em agropecuária, em situações potenciais de aprendizado, em que os conceitos de calor e temperatura foram o foco temático. A intenção era a de que o fenômeno se mostrasse ao investigador em termos de significados. Não há elaboração de hipóteses a respeito do que se busca. O conhecimento desejado éa essência do fenômeno ${ }^{5}$. O desvelar desse fenômeno é conseguido por meio de descriçóes ingênuas, descrições de experiências que os sujeitos viveram, pois nelas estão as essências do que se busca conhecer e a intencionalidade do sujeito. Aquele que descreve sua experiência é situado e os significados das suas vivências emergem do seu real vivido.

Captada pela escrita e pela fala, a descrição nos dá indicativos de como o sujeito percebe o fenômeno, o que vai se revelando na medida em que essas descrições são analisadas. "O pesquisador usa a descrição como um ponto de acesso às situaçōes vividas pelo sujeito.

\footnotetext{
${ }^{4}$ Mundo-vida, (lebenswelt) não meramente o mundo dos objetos disponiveis em sua concretização mundana, mas a totalidade das percepçôes vividas (GARNICA, 1999, p. 116).

${ }^{5}$ Martins e Bicudo (1994, p. 36).
} 
Coloca-se no mundo do sujeito e assume esse mundo de maneira tão vital quanto possível" (MARTINS e BICUDO, 1994).

Os sujeitos dessa pesquisa foram alunos que faziam parte de um dos grupos que já se encontrava constituído para desenvolver as atividades propostas pelo professor da disciplina de Física, naquele ano letivo. O grupo formado por quatro alunos, com dezesseis anos de idade, foi acompanhado durante as aulas de Física e em encontros semanais durante os anos de 1999 e 2000. Esses encontros foram registrados em vídeo, áudio e anotaçôes dos próprios alunos e da professora/pesquisadora. Nos acompanhamentos semanais, não havia uma preocupação em ensinar Física, estratégias de aprendizagem ou treinamentos, o que buscávamos compreender era o sentido de aprender para alunos, o significado desse aprender para eles. Os registros dos encontros, as anotaçóes dos alunos e entrevistas constituíram o material de pesquisa do fenômeno estudado e a descrição de cada momento foi registrada em forma de textos. A convivência e atividades realizadas com os alunos foram divididas em momentos: entrevistas e acompanhamento dos alunos em atividade de ensino dentro e fora da sala de aula.

O acompanhamento dos alunos "em sala de aula" teve como objetivo ouvir os estudantes, os sujeitos da pesquisa, aqueles que aprendem. Foi o momento de estar em contato com o fenômeno, buscar o que eles descrevem (de forma natural, espontânea) de seu aprender, o momento de buscar os significados atribuídos pelos sujeitos no seu mundo-vida. Isso porque o interesse está voltado para o sujeito que está aprendendo, que está vivenciando o fenômeno.

Durante o primeiro momento da constituição de dados, os estudantes foram acompanhados em diferentes atividades como: a. respondendo questóes; b. leitura de texto; c. laboratório demonstrativo; d. elaboração de relatório.

No segundo momento da constituição de dados, foi utilizada a entrevista como instrumento, e o objetivo foi a busca por significados, a partir da reflexão dos alunos sobre o aprender do ponto de vista deles próprios. Para isso, foi necessário obter-se descrições detalhadas, bem organizadas, da experiência vivida pelos sujeitos. Nomotética.

Situado o fenômeno e recolhidas as descriçōes, iniciamos as análises Idiográfica e

\section{As análises idiográfica e nomotética}

A análise idiográfica trata dos aspectos individuais da pesquisa realizada. Esses aspectos foram constituídos por textos que relatam e transcrevem os momentos e diálogos em que os sujeitos foram acompanhados. Trata-se de analisar as idéias que permeiam as descrições ingênuas dos sujeitos.

Terminadas as transcrições, procedemos à leitura cuidadosa das descrições por inteiro, várias vezes, para que pudéssemos nos familiarizar com os textos que descrevem a experiência vivida. Nesse momento, o que procuramos é nos colocar no lugar dos sujeitos pesquisados, na tentativa de viver suas experiências, é o momento em que buscamos compreender a linguagem do sujeito ${ }^{6}$. Em seguida, essas descriçōes foram lidas com um olhar atento e dirigido pela interrogação, pelo fenômeno em suspensão. Quando assim procedemos, buscamos nos dados obtidos não mais que o fenômeno em suspensão. A direção tomada é pela busca de significados, ou seja, de expressões claras sobre as percepções que os sujeitos têm do que está sendo pesquisado, expressado por eles próprios.

\footnotetext{
${ }^{6}$ Para saber mais, ver Martins e Bicudo (1994).
} 
Borges, R. C. P.; Carvalho, W. L. P.

Buscamos constituir e destacar as unidades de significados, que são unidades do texto que fazem sentido a partir da interrogação maior do trabalho, e que se apresentam como dados. Essas unidades são frases que se relacionam umas com as outras, indicando intersecções de idéias que fazem sentido diante da interrogação. São "discriminações espontaneamente percebidas nas descrições dos sujeitos (...)" e constituem-se em unidades de significados, que "existem somente em relação à atitude, disposição e perspectiva do pesquisador"7 .

Quando construímos as unidades de significado, realizamos uma análise das mesmas, de maneira que a descrição ingênua do sujeito assuma a forma de um pequeno texto, e em que a orientação seja dada pela nossa interrogação. $O$ fenômeno a ser compreendido, posto em suspensão, o "aprender", também leva a uma redução, pois passamos, então, a buscar "o significado de aprender para os alunos", nos dados constituídos.

As descrições dadas em termos ingênuos, assim como apresentadas em Martins e Bicudo (1994, p. 37), foram passadas para um discurso estruturado, no qual tivemos a intenção de revelar a essência e as articulações da experiência ou situação descrita. Também aqui se observa um movimento de redução, as unidades são agrupadas de maneira a dizerem algo a respeito da interrogação. $\mathrm{O}$ quadro a seguir, por exemplo, apresenta um movimento de redução em que as sínteses das unidades de significado se transformam em proposições. É a síntese na qual se integram os insights ${ }^{8}$ contidos nas unidades de significado, transformandoas em descrições da estrutura situada do fenômeno.

\begin{tabular}{|c|c|c|}
\hline Discurso na linguagem do sujeito & Unidades de significado & $\begin{array}{c}\text { Asserçóes articuladas do } \\
\text { discurso }\end{array}$ \\
\hline $\begin{array}{l}\text { (80) P-Por que têm coisas que você esquece e outras que você } \\
\text { não esquece? } \\
\text { J-Têm coisas que você se interessa e outras não se interessa. Por exemplo, } \\
\text { Matemática, me interessa, eu gosto de Matemática, eu pratico, e aí, eu } \\
\text { tenho certeza que aprendi. J - Aprendo com mais facilidade cálculos. } \\
\text { P- Por quêe J - Sei lá. } \\
\text { P - Você consegue explicar o porquê dos cálculos que está fazendo? } \\
\text { Balança a cabeça negativamente... } \\
\text { J - Não, só vou fazendo, não penso no que estou fazendo, mas tenho } \\
\text { facilidade para aprender. }\end{array}$ & $\begin{array}{l}\text { (Têm coisas pelas quais se } \\
\text { interessa e outras não. } \\
\text { Matemática interessa, o } \\
\text { aluno, gosta, pratica e aí } \\
\text { aprende. } \\
\text { Aprende com facilidade } \\
\text { cálculos. }\end{array}$ & $\begin{array}{l}\text { O gostar está relacionado } \\
\text { ao que interessa, ao que se } \\
\text { pratica e ao que se } \\
\text { aprende. Aprende-se } \\
\text { quando se consegue fazer. } \\
\text { Não se pensa no que faz. }\end{array}$ \\
\hline
\end{tabular}

Quadro I - Discurso na linguagem do sujeito/Unidades de significado/O discurso do sujeito construído a partir das unidades de significado: asserções articuladas do discurso.

As análises dos dados constituídos pela descrição levaram-nos à elaboração do que chamamos de discurso interpretativo do individual de cada sujeito. Diante da análise das unidades de significados apresentadas em asserções do discurso, como mostradas no Quadro I, elaboramos um discurso interpretativo, em que articulamos as asserções destacadas, indicando, o mais fielmente possível, as idéias articuladas no discurso, procedendo, portanto, à análise dos individuais nos discursos de cada sujeito. A constituição do discurso

\footnotetext{
${ }^{7}$ Martins e Bicudo, 1994, p. 99.

${ }^{8}$ Insight diz respeito ao que o sujeito deseja falar. É, em grande parte, de caráter intuitivo, é tanto uma descoberta quanto uma criação, pois o pesquisador, ao mesmo tempo em que descobre, atribui significado àquilo que está descobrindo e vendo.
} 
interpretativo do individual, à luz da interrogação, permite colocar de modo mais esclarecedor as idéias dos sujeitos a respeito do que buscávamos entender: o aprender. Em seguida, buscamos chegar aos invariantes e, por fim, às categorias abertas, que representam convergências e divergências das unidades de significados já analisadas e interpretadas, indicando aspectos estruturais do fenômeno investigado.

Com os dados advindos da análise idiográfica, construímos as unidades de significado, sustentadas por convergências alcançadas mediante análise e respectivas interpretaçôes. As convergências nos indicaram as categorias abertas, pontos articuladores de significados no contexto do trabalho e indicam "o que é aprender", "condições para aprender", e "as relações afetivo-relacionais no aprender".

$\mathrm{Na}$ análise nomotética lidamos com os dados advindos da análise idiográfica, ou seja, da análise do individual, indicando com isso um movimento de passagem do individual para o geral. O fim a que se deseja chegar é a estrutura geral psicológica"9, estrutura que resulta da compreensão das convergências e das divergências que se mostram a partir das significações individuais.

As asserçõoes elaboradas na análise individual são agrupadas segundo temas que explicitam no nosso pensar os significados essenciais para dar conta da compreensão sobre o sentido dado ao aprender pelos próprios alunos.

\begin{tabular}{|l|l|}
\hline Grandes categorias & Exemplos de expressóes sintéticas do que é aprender \\
\hline Sentido de aprender & $\begin{array}{l}\text { Aprender é saber falar, fazer, explicar. } \\
\text { Aprender é entender, compreender, meditar. }\end{array}$ \\
\hline Circunstâncias & $\begin{array}{l}\text { Aprender requer: interesse, seriedade, fazer, praticar, } \\
\text { repetir, treinar, ver e observar. }\end{array}$ \\
\hline Relaçōes interpessoais & $\begin{array}{l}\text { Aprender depende do professor. } \\
\text { Trabalho em grupo facilita o aprender. }\end{array}$ \\
\hline
\end{tabular}

Quadro II - As grandes categorias.

Nesse estágio do trabalho, o que possuíamos não eram resultados de "uma realidade privada de um sujeito, mas a de vários outros sujeitos". A estrutura psicológica individual pode, como um todo, pelo menos em princípio, pertencer a vários outros indivíduos (MARTINS e BICUDO, 1994, p. 107).

Em torno dessas categorias, elaboramos interpretaçôes que se articulam com as unidades de significados, com as análises já feitas, com as interrogações, autores lidos, depoimentos e com a nossa reflexão.

As convergências a que chegamos evidenciam um sentido de aprender, apontado pelas unidades de significado que dizem sobre "o sentido de aprender"; aos circunstanciais apontados pelas unidades de significado que dizem sobre as "condições para aprender"; e as relações interpessoais apontadas nas unidades de significado que dizem respeito às "relações interpessoais" no aprender. Passamos então às interpretações dessas convergências, que dizem sobre o aprender.

\footnotetext{
${ }^{9}$ Martins e Bicudo, 1994, p. 106.
} 
Borges, R. C. P.; Carvalho, W. L. P.

\section{O sentido de aprender}

A primeira das convergências, "o sentido de aprender", traduziu-se em "saber" e "entender". Esse saber se refere a um domínio de algo por parte de quem aprende. Conseguir falar a respeito do que se aprendeu é um objetivo a ser alcançado, assim como saber fazer.

O que se interpreta desse "aprender" como "saber" é um esforço em conseguir "falar" o assunto aprendido e "fazer" entendido como: resolver um exercício, executar sozinho uma atividade prática.

Sei que aprendi, quando domino totalmente o assunto. Se eu explicar para alguém, aprendi, se não souber explicar, eu não aprendi. ${ }^{10}$

Conseguir falar a alguém o que estudou dá ao estudante a segurança de ter aprendido, pois consegue promover certa estruturação àquilo que acredita ter aprendido. Nesse sentido, o aprender está relacionado a conseguir reproduzir, a repetir, e isso garante que houve aprendizagem. Saber explicar significa saber falar, porém é possível explicar sem que haja compreensão do que se explica. Essa afirmação pode encontrar respaldo quando nos reportamos, assim como Neves (1991), à construção histórica da ciência, como, por exemplo, no caso dos fenômenos físicos que foram explicados a partir de ferramentas mecanicistas, sem, entretanto, haver uma verdadeira compreensão desses fenômenos.

$\mathrm{O}$ ato de decorar é considerado pelo aluno como uma maneira de estudar que the permite dar conta de executar as tarefas propostas, e assim alcançar o que se deseja: tirar nota, ser aprovado etc.

As disciplinas, os assuntos que não são e os que não podem ser trabalhados na prática, e aplicados pelo aluno, são difíceis de aprender, o que leva à opção de decorá-los para a prova: uma matéria que não dá para ter prática é mais dificil de aprender, por exemplo, (Geografia, História), então eu costumo é decorar, decoro, chego na prova, faço a prova e depois da prova esqueço tudo.

A memorização, porém, pode se dar de diferentes maneiras e com diferentes prazos. Uma das maneiras utilizadas pelos estudantes para promover a memorização é a leitura repetida do que se quer memorizar (... para aprender, tenho que ler várias e diversas vezes. Tenho que voltar ao assunto diversas vezes até ficar na mente), ou seja, o aluno lança mão de estratégias que incrementam a probabilidade de recordar literalmente a informação, sem introduzir alterações essenciais nela, ou de tentar inseri-la numa estrutura aceitável do ponto de vista da ciência.

O estudante diz que procura entender e não decorar. Entender, no entanto, pode ser interpretado como a procura do estabelecimento das relaçôes necessárias à memorização, sem, entretanto, modificação da informação nova ou da que já possui.

Porém, quando alguém utiliza estratégias para decorar, como a do "repassamento", que consiste em recitar ou nomear os itens que se quer guardar, ele mantém a informação por mais tempo na memória de curto prazo e facilita a passagem da informação para a memória de longo prazo e, posteriormente, a sua recuperação.

\footnotetext{
${ }^{10}$ As unidades de significado foram retiradas dos discursos dos sujeitos e serão apresentadas destacadas em itálico nessa articulação.
} 
Decorar é um processo ao qual o estudante dá muita importância, pois muitas condiçôes que se apresentam no ambiente escolar o levam a ter de se utilizar dele: (...) falta tempo, a gente lê na sala de aula, grifa, depois precisa de tempo para discutir, anotar, escrever, como vamos fazer? Só ficar na cabeça? Como que eu vou fazer? Por exemplo, a história, eu não estou interessado..., por exemplo o Martinho Lutero... (e balança a cabeça negativamente). Não, olha... a fisica, algumas leis da geografia, mas história... ai.

O "saber fazer" indica outro sentido do "saber" e o que se pretende é conseguir fazer sozinho, o que significa saber executar, quando requisitado. Aprende-se quando se pratica, quando se consegue explicar o que aprendeu. $\mathrm{O}$ próprio aluno sabe que aprendeu, quando coloca esse aprendizado em prática, quando consegue resolver um exercício, uma prova, repetir uma resolução, um procedimento, uma explicação.

$P$ - Como você sabe que aprendeu ou não alguma coisa?

A - Colocando em prática... Ah! Uma prova (...) Resolvendo exercícios. (...) Depois o professor deu um exercício e eu consegui fazer, então eu sei que aprendi (...) Logo ele passou de novo e eu busquei, aprendi e agora fiz de novo...

Colocar em prática significa conseguir fazer de novo, sozinho, aquilo que o outro lhe ensinou a fazer. Significa resolver novamente um cálculo matemático, explicar novamente um procedimento experimental, um procedimento técnico, responder uma questão da prova: se eu aprendi, vou colocar em prática no trabalho (dá um exemplo de trabalhar com gado). Aprendo com mais facilidade os cálculos (...) só vou fazendo, não penso no que estou fazendo, (...) mas tenho facilidade para aprender.

A prática de que se fala se reduz à manipulação de regras ou técnicas que levam à mecanização dos atos e dos pensamentos. Para os alunos, é possível saber fazer sem, entretanto, compreender o que se faz. Aprende-se a fazer, porque se tem determinado tipo de compreensão do que se faz. Entretanto, não se tem a compreensão do significado do que se faz.

A prática, então, por ser esvaziada de significados, favorece a repetição de passos predeterminados e não permite a criação livre de situações experienciais, o que leva à não reflexão sobre o que se pratica, tornando a ação do homem um ato mecânico.

Ligada a essa concepção de aprender, encontramos um conhecimento pragmático, uma condição para aprender que revela a presença da prática e uma busca pelo conhecimento prático (...) o meu conhecimento vai aumentando e isso é importante para o vestibular, para usar algum dia. O conhecimento é importante para subir, arrumar emprego) que nos leva a um conhecimento que, segundo Greuel (1997), preconiza o conhecimento quantificável e armazenável que sirva de know how, pois o valor do conhecimento é medido pela sua operacionalidade.

No ensino de Física, assim como no de Ciências, o conhecimento científico é colocado na forma de "teoria", expressado por proposições lógicas, não estabelecendo ligações com a experiência de vida dos alunos, o que acarreta, segundo Machado (1989), uma ausência de significados no conteúdo e, conseqüentemente, o aluno não supera o nível da informação, passando para o nível da compreensão. 
Borges, R. C. P.; Carvalho, W. L. P.

O "saber fazer" não requer necessariamente saber por que se faz, como se faz de um modo e não de outro, ou a compreensão do significado do que é estudado; mas fica restrito a preencher os requisitos da tarefa de estudar. ${ }^{11}$

A partir do momento que o professor entrega o texto, eu sei que vou ter que ler, para entender, responder questôes; eu leio porque quero, ninguém me obriga... Logicamente, se o professor der um texto para a gente, não vai ser em vão; ele vai cobrar de alguma forma aquele texto em forma de trabalho, prova.

Assim, prever o tipo de perguntas que podem ser formuladas, o que o professor considerará relevante, é mais importante do que compreender o conteúdo.

Outro significado do "entender" está relacionado a uma concepção que envolve "meditar e compreender" e que vai além de "saber", difere-se do "decorar" e requer pensar sobre o que se faz ou fala. $\mathrm{O}$ "meditar" revela-se como algo além do "decorar" e aparece quando o aprender significa compreender.

Quando quero aprender alguma coisa... se surge dúvida, esclareço as dúvidas; ai a gente tenta entender. Você lê, você medita, vê qual é a dúvida que vai surgir, esclarece na sua mente. É, por exemplo, se no livro fala sobre uma experiência, (...) você vai imaginando, vai ter em mente.

Esse sentido de entender aparece nas asserções, entretanto, poucas vezes é abordado pelos alunos, por força do sistema escolar, no entanto, esse sentido de aprender parece nos indicar algo profundo e de valor.

Na busca por entender os significados, consideramos que, segundo Greuel (1997), meditar envolve um autodomínio que consiste em desenvolver formas de atenção independentes das influências somáticas, ou seja, uma emancipação sucessiva da dependência da consciência de processos fisiológicos. O verdadeiro estado de meditação se atinge quando a consciência se torna aberta para os aspectos da realidade que não são ponderáveis e palpáveis.

Assim, não basta constatar o que os sentidos transmitem, mas é preciso, também, observar as relações entre os dados percebidos, pensar. Vou lendo e imaginando o que estou lendo, dentro da cabeça, e sei que não entendi quando não consigo imaginar nada, não tem nada no meu conhecimento que possa falar sobre aquilo.

O meditar envolve o pensar sobre o que se aprende e sobre o aprender. Baird e White (1996, p. 191) acreditam que aprender com compreensão deriva de um processo de investigação decidida para um resultado de metacognição adequada. A investigação decidida compreende reflexão e ação operando juntas. A reflexão envolve pensar e compreender. Envolve perguntar-se "o que estou fazendo?" e "por que estou fazendo isto?". Envolve selecionar procedimentos para responder a essas perguntas, avaliando os resultados de procedimentos aplicados e tomando decisões para os próximos. A ação refere-se ao que se está "fazendo", observando, manipulando, aplicando procedimentos e tomando decisões. Segundo os autores, esse processo de investigação decidida gera um nível desejável de metacognição. A

${ }^{11}$ Uma tarefa é um conjunto coerente de atividades que conduz a um resultado final observável e mensurável. Os elementos básicos que estão sempre presentes na sua realização são: o estímulo ou situação desencadeadora, as seqüências das atividades e o produto que indica que a tarefa foi executada (COLL e ROCHERA, 1996, p. 340, In: COLL, PALACIOS, MARCHESI (orgs.) op. cit.) 
pessoa saberá sobre estratégias de aprendizagem efetivas, estará "consciente de", e será capaz de exercer o controle sobre a natureza e processo da tarefa de aprender.

Entretanto, o conhecimento, no sentido do que se aprende, tem importância para os estudantes, mas essa importância gira em torno do que é aplicável, do que pode ser utilizado, do que lhe pode servir para propósitos práticos. Esse tipo de pensamento é indispensável, já que tem permitido o desenvolvimento de complexas e abrangentes pesquisas em diversas áreas do conhecimento.

Isso deixa a gente doido... Essas coisas de ir lá no fundo, pegar, voltar... (balança a cabeça negativamente, demonstrando desaprovação). Essas coisas profundas.. (balança novamente a cabeça). Eu gosto de falar sem pensar. (...) Se for coisa que tem que pensar e ir lá no fundo, eu vou é atrás do professor e ai ele me explica e pronto.

Esse pensamento calculado, segundo Heidegger $(1955)^{12}$, é característico de todo pensamento que planeja e investiga. Permanece calculador mesmo não trabalhando com números. Computa novas possibilidades, mais promissoras e mais econômicas. Vai de um processo para outro, nunca pára, nunca se recolhe, não contempla o significado das coisas.

Relacionando esse conhecimento com o conhecimento operacional, que é muito valorizado na sociedade em que vivemos, entende-se que o estudante é impelido inconsciente, ou até conscientemente, a buscar tal conhecimento a partir de uma concepção de aprender que não considera o entendimento como uma etapa da compreensão, que envolve o ato de meditar, mas que considera, também, o conhecimento aplicável, como algo que pode ser utilizado.

Para os alunos que aqui se expressaram, aprender significa, portanto, saber falar, explicar, saber fazer e, eventualmente, meditar visando à compreensão, o que requer pensar com determinado compromisso. Entretanto, os estudantes indicam que esse caminho requer condições especiais, que muitas vezes não são encontradas no ambiente escolar, o que os leva a optar pelo "saber", conforme tratado anteriormente.

\section{Condições para aprender}

A segunda convergência a que chegamos nesta investigação sobre o aprender está relacionada às condiçóes para aprender. $\mathrm{O}$ interesse pelo que se aprende, ou seja, o envolvimento do sujeito da aprendizagem no próprio processo de aprender mostra-se como algo fundamental.

Para esses alunos da EAFC, o interesse reside naquilo que diz respeito à área técnica, porque há o potencial de ser utilizado no exercício da profissão, ou seja, promete ter utilidade prática: Me interesso pelo assunto, porque vou precisar quando for técnico. Quando estou interessado, não decoro, pois vai me ajudar como técnico. Para mexer com bovino não preciso saber de Martinho Lutero, Inglês. (...) $O$ ano passado tinha mais aulas práticas nas disciplinas ligadas ao campo e então era mais fácil, agora este ano está igual. Não tem mais prática no campo e então agora eles (refere-se aos professores) não estão se importando se o aluno está aprendendo ou não, eles, estão forçando o aluno a decorar, decorar e passar. Tipo manipular o aluno para não ter nenhum conhecimento, a não saber nada.

${ }^{12}$ Um discurso comemorativo de Martin Heidegger. Tradução de Maria Aparecida Viggiani Bicudo. In: Leoldianvm, Revista de Estudos e Comunicações. v. X, n. 28, Santos: ago. 1983. 
Borges, R. C. P.; Carvalho, W. L. P.

No contexto de uma prova, ou da realização de uma tarefa proposta pelo professor, um aluno se expressa assim: Me interesso por estudar determinado assunto ou matéria se for "cair" na prova. Quanto àquilo que pode ser observado, visto, presenciado, o aluno se refere à seguinte condição: Com o laboratório é mais interessante, vou percebendo, montando, fazendo, vendo... Sobre um assunto polêmico, que leva a discussões, ou relacionado ao "dia-a-dia", ligado diretamente à sua vida, o aluno refere-se como: Colei no módulo de bovinocultura, disse a professor, porque iria me prejudicar, tratava-se de um assunto ligado ao dia-a-dia, que deveria saber.

A futura atuação como técnico dirige o foco de seu interesse, e quando a atividade proposta não é ligada a essa área, o "interesse" passa a ser dirigido por "forças" externas, a nota, não menos importante para o aluno: Têm matérias que são interessantes, outras não vou precisar, mas se não estudar reprovo, essas são mais fáceis decorar.

$\mathrm{Na}$ busca por entender o que leva ao interesse, deparamo-nos com a existência de uma relação entre o interesse pelo que se está aprendendo, o tipo de aprendizagem escolhida e as metas perseguidas pelos alunos. A motivação ou rejeição do que se lhe apresenta e a persistência na realização estão relacionados a tudo isso.

$\mathrm{O}$ interesse está relacionado àquilo que pode ser útil, às características da atividade de ensino proposta, aos requisitos da avaliação. Conforme o que o estudante percebe do contexto e do propósito da tarefa de aprender, ele age em relação a ela, ou seja, diante da tarefa, um propósito emerge e exerce influência sobre a maneira como a aborda. Diante da proposta da leitura de um texto, por exemplo, o pensamento é: ... Geralmente ele vai dar um trabalho, uma prova sobre aquele texto, então temos que saber sobre o assunto... Logicamente, se o professor der um texto para a gente, não vai ser em vão, ele vai cobrar de alguma... Se o professor entregar uma folha para mim e não for cair na prova, eu não leio, não. Eu não sinto curiosidade, não.

O propósito percebido pode não levar a uma relação com as necessidades daquele que aprende, ou à compreensão do que ela implica, e, nesse caso, o que emergem são as indicações do professor e, como não podem ser relacionadas às finalidades a que correspondem, levam a um enfoque superficial. O que se utiliza, então, é a memorização da informação, necessária para provas e exames. A tarefa é encarada como imposição externa.

A intenção que tem o aluno ao enfrentar as situações de ensino e aprendizagem pode, então, estar relacionada à motivação intrínseca ou extrínseca. A motivação é entendida como um elemento pertencente ao universo do aluno, porém envolve os significados atribuídos aos papéis dos professores, dos colegas e ao papel desempenhado por eles próprios. Envolve também aspectos de caráter emocional, como as representações que faz da situação, as expectativas geradas por elas, seu próprio autoconceito e tudo mais que lhe permita encontrar sentido, ou não, na situação de aprender.

A motivação gira em torno do que pode ser aplicado imediatamente, do que pode ter utilidade prática, da obtenção de nota, da aprovação no vestibular e da possível atuação como técnico nas competências que lhe foram ensinadas. No que se refere ao conteúdo, o interesse relaciona-se ao conhecimento prático. Em razão de uma visão pragmática dada ao conteúdo, o interesse é pelas disciplinas em que a aplicabilidade do conhecimento percebida é imediata: (...) Eu não sabia aquilo lá, mas aí... eu aprendi..., é um conhecimento a mais e talvez 
aquele conhecimento possa cair num vestibular, ou algum teste que eu tenha necessidade desse conhecimento. (...) Fui lá e tirei uma cópia porque eu vou ser técnico, vou precisar.

A prática é um outro componente envolvido nas condições para aprender. Está relacionada às aulas de laboratório, às aulas práticas, à visão "concreta". Praticando, eu pratico fazendo experiência com o grupo, pegando material e fazendo de novo o experimento. As pessoas adquirem conhecimento através de práticas, não somente através de livros, os livros ajudam bastante, mas não o suficiente. No ano passado tinha mais aula... e então era mais fácil, agora esse ano está igual. Não tem mais prática... e então agora eles (refere-se aos professores) não estão se importando se o aluno está aprendendo ou não, estão forçando o aluno a decorar, decorar e passar. Tipo manipular o aluno para não ter nenhum conhecimento, a não saber nada.

Se o que se pretende é que o conhecimento possa ter utilidade, aplicação prática, o exercício dessa prática pode ser uma maneira de aprender melhor, mas a compreensão do que se vê ou ouve não está acompanhando sempre a ação de praticar.

\section{As relaçõos interpessoais}

As relações interpessoais são também uma convergência a que chegamos na busca pelo significado de aprender. As relações, professor-aluno, aluno-aluno, são fatores que estão presentes no processo de aprender e desempenham um papel importante.

Como os alunos se percebem (autoconceito) - como competentes ou incapazes - e como percebem os outros são fatores que estão presentes no processo de aprendizagem e influenciam o modo como aprendem. Nesse sentido, as interaçôes que ocorrem no processo de aprendizagem podem ser consideradas fatores que interferem no aprender. As representações mútuas dos que estão envolvidos na interação, no processo de aprender, interferem nessa mesma interação. Porque vai que outro aluno vê e fala que ele é burro.

O professor tem um papel fundamental no processo de aprendizagem, pois é ele quem explica, conduz, controla e avalia. Para aprender, preciso pensar, mas não é lá no fundo, se for preciso pensar e ir lá no fundo, procuro o professor, que me explica. Mas algumas vezes o professor não responder, aí a gente vai procurar para aprender.

Um fator importante no que diz respeito à interação professor-aluno e às representações mútuas está relacionado ao fato de os estudantes, muitas vezes, agirem de acordo com as expectativas do professor e neste caso, responderem aquilo que julgam que o professor espera.

Ao papel atribuído ao professor, pelo aluno, encontramos certa transferência de responsabilidade do aluno ao professor pelo modo como se aprende, uma vez que o aluno segue orientações já determinadas. $\mathrm{O}$ objetivo do que se faz é limitado à execução da atividade que se desenvolve. $\mathrm{O}$ professor, com ou sem intenção, acaba interferindo na maneira como o estudante valoriza a atividade ensino e se motiva com ela, e a preferência do professor é percebida pelo estudante que modifica sua ação. Geralmente, a gente pergunta para o professor. Se o professor não responde, ai a gente vai ter que pesquisar. (...) às vezes é bem mais fácil perguntar para o professor, a gente tem necessidade de procurar, pesquisar, mas quando se fica para recuperação, a gente não vai perguntar para o professor, ai a gente vai pesquisar. Geralmente, a gente faz isso quando tá num caminho bem mais difícil, na recuperação. Só quando a "corda está no pescoço". 
Borges, R. C. P.; Carvalho, W. L. P.

O professor é aquele que define os caminhos a serem seguidos, que facilita a aprendizagem, aquele que controla os alunos, que mantém a disciplina. É visto pelos alunos como aquele que sabe e que pode ensinar, enquanto o colega de classe não sabe mais do que o próprio aluno e, portanto, não lhe pode ensinar. Se o professor deixa o aluno colar e não fala nada... Se tirasse a prova e desse zero, o aluno não seria obrigado a estudar na recuperação e aí aprender? Seria um meio de ajudar. Conseguir aprender, a gente aprende, mas não totalmente, não o que o professor sabe; porque cada um tem uma forma de pensar diferente, um já compreende a matéria melhor que a gente. (...) Geralmente, quando tenho dúvidas, interesse de perguntar para os colegas eu não tenho, não. Perguntar para o professor eu tenho mais segurança, porque o professor já fez a faculdade, ele entende daquilo. Se perguntar para o colega vai ficar sempre a dúvida se está certo, agora o professor, não. Pode ser que ele (refere-se ao colega) saiba, mas...

Porém, a interação entre alunos nos trabalhos em grupo demonstrou que os estudantes, a princípio, necessitam de que o professor atue como orientador do trabalho, no sentido de guiar-lhes nos procedimentos. No acompanhamento realizado, quando o grupo elaborava a atividade de relatório a respeito de um experimento observado em sala, pode-se notar essa necessidade.

(Os alunos sentam-se ao redor da mesa, levam alguns livros de Física. Permanecem em silêncio, folheando os livros. Um dos alunos copia trechos do livro).

A2 - O que você está copiando aí?

A1 - Dá um tempo.

Então o A2 pega seu caderno, abre e diz o que vai fazer

A2 - Cada um lê, e anota no caderno.

A3 - Ler o quê?

Dão risada...

$\mathrm{O}$ aluno A2 pensa... e começa a escrever.

(Os alunos A3 e A4 ficam folheando os livros, dispersos, às vezes dão risada, conversam. $\mathrm{O}$ aluno A1 lê o texto, anota; o aluno A2 pensa e anota, pergunta algumas coisas para a professora, sobre as quais tem dúvidas. A1 coloca sua opinião e o assunto é discutido.)

Quando o grupo tem a ajuda de alguém que os oriente, as discussões ocorrem. Nesse sentido, a interação em grupo pode promover a aprendizagem. Essa interpretação é permitida quando se considera que os trabalhos em grupo são propícios à existência de momentos em que o tempo é destinado a refletir sobre o que se aprende; o ritmo do aprender, na medida do possível, é ditado por quem aprende. $\mathrm{O}$ aluno, consciente, inconscientemente ou por força das circunstâncias acaba tomando as rédeas do processo. Pode acabar tomando o objetivo da atividade como seu próprio objetivo, o que poderá motivá-lo a aprender. A argumentação para falar com o outro acaba acontecendo, e a meditação é facilitada nessa interação. $O$ debate é a melhor forma de você, entre amigos, de tirar dúvidas. Primeiro, cada um lê, e depois, cada um coloca a sua idéia, ai depois, se faltar alguma coisa, a outra pessoa complementa, isso facilita a mente da pessoa a entender o que é o assunto.

Entender o que se aprende é outro sentido do aprender. É possível perceber diferenciaçôes na abordagem da tarefa, ou seja, querer compreender o que se lhe apresenta, ou decorar. A escolha por uma ou outra abordagem, que leva a um ou outro sentido de aprender, 
pode ser influenciada, muitas vezes, pela intenção de obter sucesso e também pelo que é percebido pelos alunos em relação à maneira como o professor age, como ensina, ao que dá valor, enfim, pelas representações mútuas professor-aluno, e também, em menor grau, aluno-aluno.

Decorar, ou "aprender de cor", requer pouco tempo de quem decora e proporciona resultados imediatos, rápidos e satisfatórios, já que leva ao sentimento de sucesso.

\section{Reflexões sobre os resultados}

Aqui, tentamos realizar algumas reflexões que envolvem a compreensão que tivemos sobre o sentido de aprender, para alunos de uma escola técnica e sobre sua relação com as questōes evidenciadas nesta pesquisa: a) os fatores cognitivos não são os únicos responsáveis pelo aprender; b) fatores não cognitivos têm tanta importância quanto os primeiros, podendo interferir significativamente no aprendizado, portanto, devem ser considerados quando se busca conhecer os significados de aprender.

O saber, o falar e o fazer revelam um envolvimento com a explicação, de acordo com os discursos dos alunos. Saber falar e fazer é importante para saber explicar, porém, não necessariamente envolve as razões do fazer ou de como fazer algo de determinado modo e não de outro. Ou seja, a compreensão do significado daquilo que se estuda não está em evidência, e então aprender se torna um ato mecânico, suficiente para o aluno viver e atuar como técnico, sem aparente necessidade de meditar a respeito dessa questão.

O meditar indica um caminho gradativo do desenvolvimento cognitivo, que envolve argumentar, estabelecer relações, pensar. Mas, por seu lado, o conhecimento para os alunos é algo pragmático, é algo que envolve uma concepção de aprender que significa exercitar, praticar. Esse conhecimento prático, quando desprovido de reflexões, se distancia do entender e se aproxima do saber. Mas este é um saber que atende às necessidades imediatas e primárias do ser, um pensamento calculador, que pode não levar ao autoconhecimento e ao conhecimento do Outro e do Mundo. Ou seja, se essa concepção de conhecimento prático for alimentada, mesmo no ensino técnico, onde ela parece cabível, haverá perdas, pois significa alimentar uma racionalidade instrumental, ou uma técnica que tende a ser desumanizada justamente porque se apóia num saber de curto alcance. Assim, um desafio para a escola técnica é o de trabalhar no sentido de que uma concepção mais ampla de conhecimento venha a fazer parte dos interesses dos alunos.

O interesse é traduzido pela participação, atenção e seriedade por parte de quem aprende. Estar interessado é uma predisposição direcionada àquilo que se vai aprender, por parte de quem vai aprender. Porém, o modo como esse sujeito se aproxima do que aprende está relacionado com as metas, com as intenções que possui, que passam pela sua percepção do objeto a ser aprendido, passam pela relação subjetiva e intersubjetiva com o outro e com o mundo.

Essa escolha pode, então, levar a um aprendizado de fato, envolvendo a compreensão do que se aprende, envolvendo a meditaçao, ou levar a uma explicação sem necessariamente compreender, pode levar a um decorar. Os alunos acabam escolhendo a forma de aprender que mais rápido lhes traz resultados satisfatórios para serem aprovados e para atuarem. Na interpretação a que nos permitimos, sinalizam que o que leva à compreensão é o melhor aprender, mas revelam que o "aprender sem compreender" é também importante e dá bons resultados. 
Borges, R. C. P.; Carvalho, W. L. P.

A situação apresentada leva-nos a refletir a respeito do que dizem os sujeitos: aprender requer entender, compreender, meditar e decorar não é aprender. Entretanto, no conjunto dos discursos, o decorar acaba se traduzindo também em um sentido de aprender, sem envolver a compreensão do que se aprende.

Podemos, ampliando essa interpretação, entender esse sentido como uma profunda crítica ao sistema educacional e à superficialidade com que é tratado o conhecimento. $\mathrm{O}$ estudante sinaliza, sem valorizar muito, que aprender requer compreender, meditar, requer aprofundar no que se estuda, requer reflexão integrada à ação. Requer, portanto, um significado não valorizado pelo sistema educacional ou pela sociedade, e por isso não considerado por ele no momento em que estuda.

Essa reflexão nos leva a uma revolta por parte de alguns sujeitos quando se vêem submetidos a um sistema que prioriza algo que não os levará a um aprender significativo; que os obriga a utilizar-se de recursos e significados de aprender não promissores. É como se $o$ professor não ligasse para o aluno, como se os que estão envolvidos no processo estivessem forçando $o$ aluno a decorar e passar, como se estivessem manipulando o aluno para não ter nenhum conhecimento $^{13}$. Aí, então, na tentativa de dar sentido ao próprio aprendizado, o sujeito considera o saber fazer, falar, explicar e até mesmo o decorar como um sentido de aprender, não significativo no que se refere ao "aprender de fato", mas como uma forma de não fracassar, de responder àquilo a que o sistema o submete e ao que a escola valoriza.

Se um aluno de escola técnica, como tarefa de aula, preparou um alimento para o gado, ou inseminou artificialmente um animal, ou ainda semeou, replantou e cultivou uma hortaliça, resolveu uma lista de exercícios, entre outras possíveis atividades desenvolvidas, não significa que tenha avançado em termos de conhecimento. O "conhecimento prático", a ação prática, segundo Piaget $^{14}$, é uma ação de primeiro grau, que constitui matéria-prima do conhecimento, que serve de apoio à ação de segundo grau, que, por sua vez, constitui a abstração ou tomada de consciência. Essa ação de segundo grau, de que fala Piaget, é eminentemente e progressivamente endógena, uma ação que tende à progressiva interiorização.

Segundo Becker (1993), uma pessoa pode atravessar a vida repetindo tarefas práticas com grandes habilidades sem, entretanto, mostrar progressos significativos no conhecimento. Um agricultor, durante toda a vida, pode desgastar os músculos no trabalho braçal, enfrentar dificuldades de financiamento, de produção ou de vendas dessa produção, e nem por isso ser capaz de delinear uma crítica à divisão de trabalho na sociedade capitalista, e "ver" o lugar do agricultor neste sistema de produção.

Entretanto, se houver reflexão sobre este conhecimento prático, o sujeito pode, com o tempo, tomar consciência e apropriar-se dos mecanismos da própria ação. Poderá compreender a estrutura e os mecanismos desse conhecimento ao estabelecer relações entre os elementos percebidos e chegar a uma generalização, podendo até teorizar a respeito dos elementos que estão envolvidos nesse conhecimento. "As primeiras explicações ou formas explicativas transformamse em conteúdo para o qual se constroem novas formas" (BECKER, 1993, p. 48), caminhando assim para novos patamares de reflexionamento.

\footnotetext{
${ }^{13}$ As unidades de significado foram retiradas dos discursos dos sujeitos.

${ }^{14}$ Citado por Becker, F. Ensino e construção do conhecimento: o processo de abstração reflexionante. Educação e Realidade, Porto Alegre: v. 18, n. 1, jan/jun 1993, p. 47.
} 
O conhecimento, nessa concepção, é o resultado de uma construção por um processo de abstração reflexionante, que ocorre na interação sujeito-objeto ou Eu e Mundo. Ocorre, então, por conta dessa interação, dessa troca do sujeito com o meio, eu e mundo, momentos de leitura perceptiva e de reflexionamento.

O aluno, futuro técnico, é treinado a fazer e a executar o que os outros pensaram. Sobre esse fazer não ocorre uma reflexão, não há a experiência no sentido de que fala Piaget. ${ }^{15}$ Entender, portanto, que se trabalha em um ambiente escolar sobre o conhecimento prático e considerá-lo como um conhecimento genuíno, ou ainda que, pelo fato de o sujeito ter conhecimento prático, ele tem também um conhecimento genuíno, é ingenuidade, pois "o saber não vem da prática, mas da abstração reflexionante "apoiada sobre" porte sur a prática" (BECKER, 1993, p. 49). Com isso, não se está dizendo que a prática não tenha importância, mas sim que esta é condição necessária, mas não suficiente, da teoria.

Quando o sujeito reflete, ele extrapola a percepção dos sentidos fisiológicos e, por meio do pensamento, percebe outros aspectos do mundo e do outro. Essa reflexão é, portanto, fundamental para o conhecimento.

O treinamento, como reconstrução escolar do conhecimento, ocorre em um "fazer sem compreender", e separa a teoria da prática e, quando isso acontece, não ocorre reflexionamento do fazer ou da prática, condição necessária ao desenvolvimento do conhecimento. Subtrai-se, assim, a matéria-prima do reflexionamento, anulando o processo de construção das condições do desenvolvimento cognitivo e, portanto, da aprendizagem (BECKER, 1993).

Esse conhecimento prático de que se fala é específico, especializado, pontual, que não permite ao aluno uma visão ampliada, com possibilidade de conhecer múltiplas realidades e atuar sobre elas. A possibilidade de se estabelecer relaçōes necessárias ao conhecimento tornase remota e a participação do sujeito "crítico, criativo, consciente, transformador"16, no mundo, fica comprometida.

Entretanto, o conhecimento prático, o "saber fazer", está sendo suficiente para o futuro técnico. "Sobrevive-se" sem compreender e por isso não é necessário se envolver profundamente no seu próprio aprender. Entretanto, essa educação que se apresenta estaria sendo ética com os alunos? Não estaria em falta com os que a ela se submetem?

Assim, torna-se difícil exigir desse técnico que ele "transcenda a mera ação motora"17, que "construa, articule e mobilize valores, conhecimentos e habilidades para resolução de problemas rotineiros e, em especial, os inusitados, em seu campo de atuação profissional, que aja eficazmente diante do inesperado e do habitual, superando a 'experiência acumulada' transformada em hábito e liberando o profissional para a criatividade e a atuação transformadora"18, pois estas competências requerem mais do que conhecimento prático: requerem reflexão sobre essas práticas, requerem a compreensão do significado do que se faz, e não somente da lógica do que se faz. A reflexão sobre o significado do que se faz, o caminho pelas questões dos "porquês" e dos "como", torna o ser humano mais pleno.

\footnotetext{
${ }^{15}$ Experiência, no sentido de Piaget, não é a prática, mas o que se faz com a prática.

${ }^{16}$ Proposta Pedagógica da EAFC, 1999.

${ }^{17}$ PCN, 1999.

${ }^{18}$ PCN op. cit.
} 
Borges, R. C. P.; Carvalho, W. L. P.

A reflexão a respeito das representações construídas pelo aluno sobre professor, o ensino e a aprendizagem levou-nos a entender a importância que as "representações" ${ }^{19}$ possuem no aprender desse aluno. Essas representações podem guiar os comportamentos de ambos, professor e aluno, em relação ao aprender e ao ensinar; e pode-se dizer que devem ser consideradas quando se busca entender o aprender. Nessas representaçóes, está presente a interpretação dada pelo aluno ao papel do professor, como aquele que sabe e que vai ensinar enquanto ele precisa somente prestar atenção e repetir o conhecimento verdadeiro, correto que o professor lhe transmitiu. Então, nesse sentido, o aluno não se percebe sujeito de seu aprender, e não se vê na necessidade de se envolver no sentido de esforço pessoal, de apresentar suas idéias, de discutir, de argumentar.

A interpretação a que nos leva a interação entre iguais, mesmo que não seja consciente da parte dos alunos, é a de que o trabalho em grupo proporciona aos alunos o tempo e a autonomia necessários para a reflexão e a compreensão. Quando se está trabalhando em grupo, o controle do professor não desaparece, entretanto aumenta o controle do grupo sobre o seu próprio aprender. Faz-se necessário decidir entre os componentes desse grupo, sobre o que se vai fazer e como se vai fazer, e algumas vezes é necessário explicar aos outros componentes do grupo o porquê se vai fazer algo de um modo e não de outro. É um momento em que se é obrigado a parar e ouvir o ponto de vista do outro, a pensar a respeito do próprio ponto de vista e até mesmo a reestruturá-lo. O trabalho em grupo, portanto, mostra-se importante pelos diferentes aspectos discutidos e ajuda também o aluno a adquirir as ferramentas verbais, regular a própria atividade cognitiva em relação à atividade que desenvolve ou ao assunto que discute. É importante, também, porque pode ocorrer uma interiorização das estratégias utilizadas nas soluções dos problemas enfrentados pelo grupo.

Enfim, a reflexão, com que nos envolvemos, nos deu o entendimento de que no processo de ensino a consciência é fundamental para que o aprender faça sentido, para que se possa refletir sobre o que se faz e sobre as implicações desse fazer. $\mathrm{O}$ conhecimento com base na reflexão fundamenta uma prática mais ampla e eficiente, pois envolve um constante estar pensando e compreendendo. Um estar se perguntando "que estou fazendo?" e "por que estou fazendo isso?".

Compreendemos, portanto, que para se entender a realidade da qual se faz parte, e para que se possa atuar nessa mesma realidade, é necessário mais do que um conhecimento prático, é necessário refletir sobre esse conhecimento, é necessário pensar. A participação ativa, que indica uma consciência de si mesmo, como agente de próprio aprender, como agente de transformaçôes sociais, pode se consumar diante da descoberta de uma realidade dinâmica, permitida pelas relações estabelecidas na atividade pensante.

\section{Referências}

BAIRD, J. R.; WHITE, R. T. Metacognitive strategies in the classroom. In: TREAGUST D. F.; DUIT, R.; FRASER, B. J. (eds.) Improving teaching and learning in science and mathematics. New York: Teachers College Press, 1996.

\footnotetext{
${ }^{19}$ Representaçôes, aqui, dizem respeito às representaçôes mútuas dos que estão envolvidos no processo de ensino e aprendizagem do aluno com relação ao "contexto" em que se insere e às interaçôes nesse contexto.
} 
BECKER, F. Ensino e construção do conhecimento: o processo de abstração reflexionante. Educação e Realidade, v. 18, n. 1, p. 43-52, jan/jun, 1993.

BRASIL. Secretaria de Educação Média e Tecnológica. Parâmetros Curriculares Nacionais: Ensino Médio. Brasília: Ministério da Educação, 1999. 364 p.

Escola Agrotécnica Federal de Cáceres (MT). Proposta pedagógica, 1999.

COLL, C.; ROCHERA, M. J. Estruturação e organização do ensino: as seqüencias da aprendizagem. In: COLL C.; PALACIOS, J.; MARCHESI; A. (orgs.). Desenvolvimento psicológico e educação: Psicologia da Educação. Porto Alegre: Artes Médicas, 1996. v. 2, pt. IV, cap. 20, p. 333-352.

GARNICA, A. V. M. Educação, matemática, paradigmas, prova rigorosa e formação do professor. In: BICUDO, M. A .V.; CAPPELLETTI, I. F. (orgs.) Fenomenologia uma visão abrangente da Educação. São Paulo: Olho D'Água, 1999. p. 105-154.

GREUEL, M. da V. Reflexão e meditação. Chão e Gente, n. 22, fev. 1997.

HEIDEGGER, M. Um discurso comemorativo. Tradução de BICUDO, M. A. V. In: Leoldianvm, Revista de Estudos e Comunicaçōes, v. X, n. 28, Santos: ago. 1983.

MARTINS, J.; BICUDO, M. A. V. A pesquisa qualitativa em psicologia: fundamentos e recursos básicos. 2. ed. São Paulo: Moraes, 1994. 110p.

MACHADO, V. de M. Ensino de ciências na escola de $1^{\circ}$ grau: visão de ciências veiculada pelos alunos. São Paulo, 1989. Dissertação (Mestrado em educação), Pontifícia Universidade Católica de São Paulo, 1989.

NEVES, M. C. D. Uma perspectiva fenomenológica para o professor em sua expressão do: "O que é isto, a ciência? Campinas, 1991. Tese (Doutorado em Educação - Área de concentração: Psicologia Educacional) Universidade Estadual de Campinas, 1991.

SIERRA, B.; CARRETERO, M. Aprendizagem, memória e processamento da informação: A psicologia cognitiva da instrução. In: COLL C.; PALACIOS, J.; MARCHESI, A. (orgs.). Desenvolvimento psicológico e educação: psicologia da educação. Porto Alegre: Artes Médicas, 1996. v. 2, pt. I, cap. 8, p. 122-137.

Artigo recebido em março de 2005 e selecionado para publicação em outubro de 2005. 
